\title{
Correction to: A study of the mechanism for plant leaf samples to form flaming combustion under external radiant heat flux
}

\author{
Jun-Jun Tao ${ }^{1,2} \cdot$ Hai-Hui Wang ${ }^{1} \cdot$ Shamima Aktar $^{1} \cdot$ Feng Zhu ${ }^{1}$ \\ Published online: 28 March 2020 \\ (C) Springer-Verlag GmbH Germany, part of Springer Nature 2020
}

\section{Correction to: Biomass Conv. Bioref. https://doi.org/10.1007/s13399-019-00500-7}

The first author would like to add Hai-Hui Wang, Shamima Aktar and Feng Zhu as authors of the current article [1]. The newly added authors were accidentally omitted in the original manuscript due to lack of recognition of their contribution. However, since the article reports the combined work of all the authors, Jun-Jun Tao would like to correct the authorship. Correspondence related to this article should be related to Dr. Hai-Hui Wang; E-mail: hhwang4@ustc.edu.cn.

More detailed author contributions and funding statements are provided below:

\section{Author Contributions}

JJT: participation in data analysis and paper drafting;

HHW: project coordination; site survey and arrangement of sample collection; design of sample tests; data analysis; formation of paper draft;

SA: involvement of further data analysis and paper draft amendment;

FZ: sample collection and preparation; involvement of sample tests and initial data analysis

The online version of the original article can be found at https://doi.org/ 10.1007/s13399-019-00500-7

Hai-Hui Wang

hhwang4@ustc.edu.cn

Jun-Jun Tao

jjtao@cslg.edu.cn

1 State Key Laboratory of Fire Science, University of Science and Technology of China, 96 Jinzhai Road, Hefei 230026, Anhui, People's Republic of China

2 School of Chemistry and Materials Engineering, Changshu Institute of Technology, No. 99rd South Ring Road, Changshu, Suzhou 215500, Jiangsu, People's Republic of China

\section{Funding}

This work was jointly supported by Hundred Talents Program, China Academy of Sciences (No. Z0050) and the University Natural Science Foundation (No. XZ1751).

In addition to correcting the authorship and declarations, the authors would like to correct the title. The original title was "Study on the transition mechanism for broadleaf foliage from smoldering to flaming combustion under external radiant heat flux" and now has been changed to "A study of the mechanism for plant leaf samples to form flaming combustion under external radiant heat flux".

\section{Technical Erratum to the Article Posting Publication}

1) In the last paragraph of the Introduction section on Page 2, a statement should be added after the first sentence, "The broad-leaf tree foliage with various shapes and containing different levels of water content is selected for the measurement".

2) In the last paragraph of the Introduction section on Page 2 , the second sentence from the end should be re-written as "Starting from the layered feature of the samples, calculations are proceeded to monitor the mass flux of volatiles liberated during the ignition of the leaf samples at various radiant heat flux".

3) Two typos should be revised in the 2 nd paragraph of the right column on Page 5; "semi-cellulose" must be "hemicellulose".

4) In the paragraph just above Figure 5 on Page 5 , a citation information [9] should be added at the end of the first sentence.

5) In the last paragraph on Page 6, the term "mass flux" should be replaced by "mass flow rate".

6) Before the last paragraph on Page 7, a subsection title should be added as " 3.3 Role of surface layer in the formation of flaming combustion of a sample".

7) In the last sentence on Page 7, the citation [24-26] must be changed to [24]. 
8) The last paragraph in the section of Results and discussion must be deleted and replaced by the following paragraphs:

"Detailed analysis on the measurements can not only confirm the reliability of the statements addressed above, but also further reveal the mechanism for the successful development of gaseous combustion during the testing of leaf samples. For fresh $O$. fragrans species, its water content is $47.6 \%$, and the volatile matter content maintains at $41.4 \%$ (refer to Table 1 ). The amount of volatile matters retained in the surface layer of a sample is then evaluated at $112.61 \mathrm{~g} \mathrm{~m}^{-2}$, i.e. $\rho_{a} \delta_{1} \mathrm{VM}=136 \times(0.01 / 5) \times 1000 \times 0.414 \mathrm{~g} \mathrm{~m}^{-2}$. In light of recent work on biomass fuels involving different plant leaves [25], the heating value of fixed carbon was evaluated at $30.50 \mathrm{~kJ}$ $\mathrm{g}^{-1}$. Thus, the heating value of volatile matter $\Delta H_{v}$ can be accurately determined as $\left(\mathrm{LHV}_{\mathrm{d}}-30.50 \mathrm{FC}_{\mathrm{d}}\right) / \mathrm{VM}_{\mathrm{d}}=20.71 \mathrm{~kJ}$ $\mathrm{g}^{-1}$, where $\mathrm{LHV}_{\mathrm{d}}=21.58 \mathrm{~kJ} \mathrm{~g}^{-1}, \mathrm{VM}_{\mathrm{d}}=76.69 \%$ and $\mathrm{FC}_{\mathrm{d}}=18.68 \%$. By integrating the heat release rates obtained at $\dot{q}_{e}=85 \mathrm{~kW} \mathrm{~m}^{-2}$ over the time period prior to the presence of PHRR and a division by $\Delta H_{v}$, the amount of volatile matters released by the sample during the same period was then evaluated at $88.75 \mathrm{~g} \mathrm{~m}^{-2}$. This result falls in the reasonable range in comparison with the available amount of volatiles retained in the sample surface layer. There is no doubt that for a low level of $\ddot{q}_{e}$, we can find a smaller amount of volatiles liberated by a sample prior to the presence of PHRR. Same variation pattern can be seen to the parallel plant species.

As partially revealed by the results in Table 2 , for those species undergoing flaming combustion, a higher external radiant heat flux implies a shorter time spent to reach ignition status and a higher magnitude of PHRR. Once a sample is exposed to the radiant heat flux at a higher level, the rate of temperature rise in the surface layer is accelerated due to its thermally-thin nature $[9,24,26]$. This process allows a faster release of the available volatile matter content retained in the layer, thus resulting in a larger magnitude of $\dot{m}_{v m}$. This understanding explains why at a low radiant heat flux, a sample may undergo smoldering only, whereas at an elevated radiant heat flux the sample is able to form flaming combustion at the initial stage of the measurement, as often observed during the tests [9].

The measurement for a fresh B. spectabilis sample at $\dot{q}_{e}$ $=85 \mathrm{~kW} \mathrm{~m}^{-2}$ indicated that, the sample omitted the initial flaming combustion by reaching the stage of smoldering directly at $14 \mathrm{~s}$. For this particular species, we obtained its $\rho_{\alpha} \delta_{1} V M$ equal to $45.42 \mathrm{~g} \mathrm{~m}^{-2}(=136 \times(0.01 / 5)$ $\times 1000 \times 0.167$ ). Considering the temperature increasing pattern of the mass flux of volatiles generated by the surface layer of a sample, the magnitude of $\dot{m}_{v m}^{\prime \prime}$ prior to the commencement of charring and the associated oxidation (smoldering) should be expected to exceed $4.0 \mathrm{~g} \mathrm{~m}^{-2} \mathrm{~s}^{-1}$. However, in light of the existing results reported in the literature $[13,15]$, the critical mass flux for flaming ignition of usual carbon-containing organic materials is only $\sim 1.5 \mathrm{~g} \mathrm{~m}^{-2} \mathrm{~s}^{-1}$. This contradiction revealed that the critical conditions for developing a flame above a leaf sample containing enormous water could have been altered by the simultaneous water liberation of the sample.

Water liberation of a sample plays a role in increasing the gas density and heat capacity in the potential flame zone. For the plant species with relatively low water content, this effect should be negligible; however, it may not be the case for a sample containing water content exceeding $75 \%$, such as B. spectabilis or S. sericea (refer to Table 1). Because its moisture content is sufficiently high, the simultaneously released moisture could have considerable impact on the energy density for establishing a flame nearby the sample surface [1315]; meanwhile, the chemical reactions in gas phase should also slow down by water dilution on the gaseous combustibles. As a result, it is difficult for a $B$. spectabilis or $S$. sericea sample to form gas-phase combustion even at very high level of $q_{e}$, as illustrated during the measurement.

As revealed in a recent theoretical work [24], the volatiles generated during the initial stage of the measurement could be more or less influenced by the adjacent inner layer, for those leaves with small surface areas and at a low level of water content. As the individual surface areas of the leaves are small, thermal shrinkage of individual leaves in the sample surface layer may cause an exposure of part of the adjacent inner layer to the external radiation source, allowing the adjacent inner layer to intercept external radiant heat directly. Meanwhile, an increase in the volatile matter content of a sample implies its lower level of water content, corresponding to a drop in the heat capacity of the sample surface layer. Assisted by the gaseous flame nearby, the adjacent inner layer moved into the pyrolysis stage at a faster pace, thus making contribution to the sample's burning intensity in gas phase at the initial stage of the measurement."

9) Some un-used symbols must be removed from the Nomenclature on Page 8, which are listed as follows: $A_{v}, E_{v} \dot{m}_{v}, Q_{v}, R, T, T_{m}, \rho_{1}, \rho_{I m}$ and $\chi$.

10) The following missing symbols should be inserted in the relevant places in the Nomenclature:

$\mathrm{FC}_{\mathrm{d}} \quad$ fixed carbon content of a leaf sample on dry basis, $\%$

$\mathrm{LHV}_{\mathrm{d}}$ net heating value of a leaf sample on dry basis, $\mathrm{kJ} \mathrm{g}^{-1}$

$R_{C O} \quad$ rate of $\mathrm{CO}$ production by a sample, $\mathrm{g} \mathrm{s}^{-1}$

$R_{\mathrm{CO} 2}$ rate of $\mathrm{CO}_{2}$ production by a sample, $\mathrm{g} \mathrm{s}^{-1}$

$\mathrm{VM}_{\mathrm{d}}$ volatile matter content of a sample on dry basis, $\%$ 
11) Missing units of the symbols in the Nomenclature should be added as the following:

$\mathrm{ASH}, \%$; FC, \%; HRR, $\mathrm{kW} \mathrm{m}{ }^{-2} ; \dot{m}_{v m}, \mathrm{~g} \mathrm{~s}^{-1} ; \dot{m}_{v m}$, $\mathrm{g} \mathrm{m}^{-2} \mathrm{~s}^{-1}$; MC, \%; $m_{\text {sample }}, \mathrm{g} ; m_{w}, \mathrm{~g}$; PHRR, $\mathrm{kW} \mathrm{m}^{-2}$; $q_{e}, \mathrm{~kW} \mathrm{~m}{ }^{-2} ; t, \mathrm{~s} ; T_{0}, \mathrm{~K} ; T_{s}, \mathrm{~K} ; \mathrm{VM}, \% ; V_{\text {sample }}, \mathrm{m}^{3} ; \delta_{1}$, $\mathrm{m} ; \delta_{a}, \mathrm{~m} ; \Delta H_{v}, \mathrm{~kJ} \mathrm{~g}^{-1} ; \rho_{a}, \mathrm{~kg} \mathrm{~m}^{-3} ; \rho_{\text {air }}, \mathrm{kg} \mathrm{m}^{-3}$.

12) The funding information on Page 8 should be re-written as the following: "This work was jointly supported by Hundred Talents Program, China Academy of Sciences (No. Z0050) and the University Natural Science Foundation (No. XZ1751).

13) References after the $23^{\text {th }}$ in the reference list on Page 9 should be deleted and replaced by the following:
[24] Tao J-J, Wang H-H, Zhu F (2016) Attenuation effect of surface layer during the leaf samples ignition by radiant heat flux. Combust. Sci. Tech. 22(2): 113-120. (in Chinese)

[25] Tao J-J, Wang H-H, Chen S, Hu G-Q, Wang Z-S, Zhou Y-F, Li X-C, Wu Z-P (2016) A study of the heating values of surface fuels in Guangdong forest areas. In: Proc. 2015 Inter. Conf. Energy, Environ. Sustain. Ecosyst. Develop. World Scientific Publishing, Singapore.

[26] Williams PT, Besler S (1996) The influence of temperature and heating rate on the slow pyrolysis of biomass. Renewable Energy 7(3): 233-250. 